\title{
Systemic Lupus Erythematosus-associated Retinal Vasculitis
}

RONALD R. BUTENDIECK, MD; KIMBERLY PARIKH, ARNP; MICHAEL STEWART, MD, Department of Rheumatology, Mayo Clinic, Jacksonville, Florida; CAROLINE DAVIDGE-PITTS, MB, BCh, Department of Endocrinology, Mayo Clinic, Rochester, Minnesota; ANDY ABRIL, MD, Department of Rheumatology, Mayo Clinic, Jacksonville, Florida, USA. Address correspondence to Dr. R. Butendieck, Mayo Clinic, 4500 San Pablo Road, Jacksonville, Florida 32224, USA. E-mail: Butendieck.Ronald@mayo.edu. J Rheumatol 2012;39:1095-6; doi:10.3899/jrheum.111462

Retinal vasculitis is an uncommon but potentially sightthreatening manifestation of systemic lupus erythematosus (SLE). The most common findings include retinal hemorrhage, "cotton-wool" spots, and vasoocclusion ${ }^{1,2}$. While the exact pathogenesis is unclear, it is thought that antiphospholipid antibodies, immune complex deposition, and complement activation are involved ${ }^{1}$. Systemic corticosteroids and cyclophosphamide are established treatment options for vasculitis, but case studies show promise with rituximab and plasma exchange ${ }^{3,4,5}$.

A 38-year-old woman with established SLE presented with acute onset of painless blurred vision and "floaters" in her right eye. She reported a 2-day history of headache, photosensitivity, arthralgia, and muscle weakness. Laboratory investigations revealed hemoglobin 9.8, erythrocyte sedimentation rate $58 \mathrm{~mm} / \mathrm{h}$, creatine phosphokinase 259 , and proteinuria. Best corrected visual acuities were counting fingers at 6 feet in the right eye and 20/30 in the left eye. Visual fields were full to confrontation; external examination showed conjunctival hyperemia in both eyes. Slit lamp examination revealed anterior chamber cells, flare, and keratic precipitates in both eyes. Intraocular pressures were

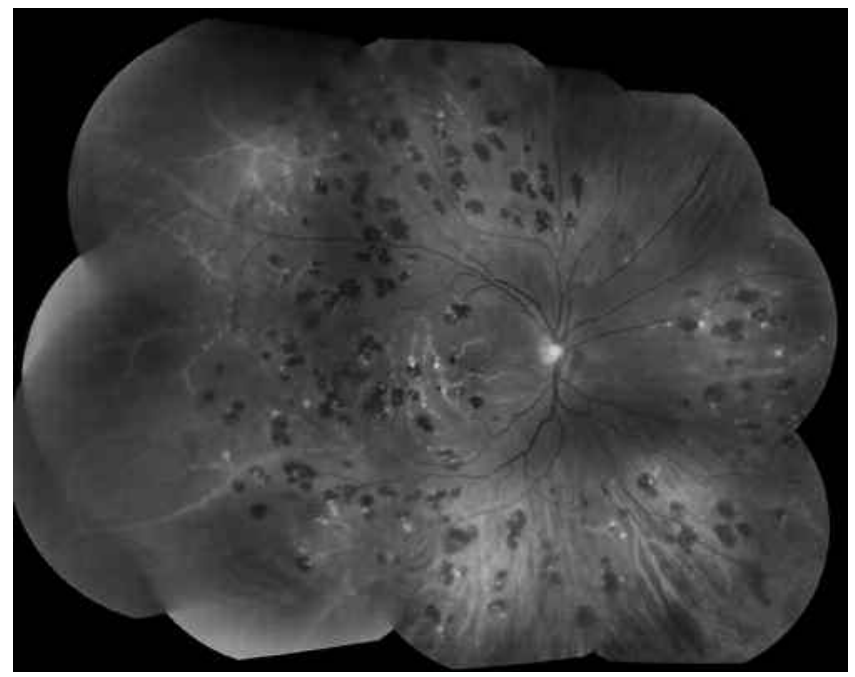

Figure 1. Fundus photography of the right eye shows widespread, white-centered retinal hemorrhages, extensive peripheral retinal vein sheathing indicating periphlebitis, peripheral nonperfusion, and ischemic macular thickening. Mild uveitis was observed in the left eye (not shown). normal. There were $1+$ white cells in the vitreous in both eyes. Fundus examination (Figure 1), fluorescein angiogram (Figure 2 and 3), and optical coherence tomography (Figure 4) were consistent with retinal vasculitis. Prednisone dose was increased from $10 \mathrm{mg}$ to $60 \mathrm{mg}$ daily and she complet-

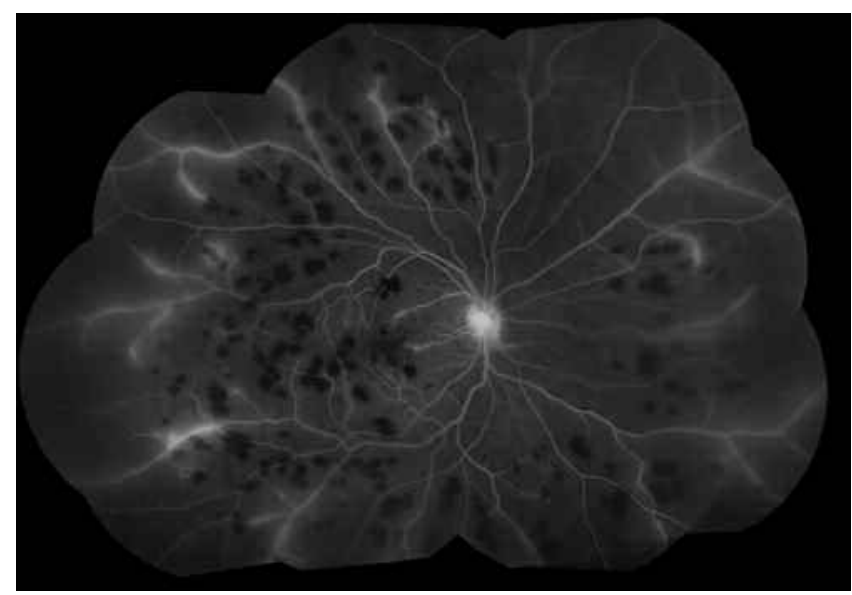

Figure 2. Fluorescein angiogram of the right eye shows patchy staining of the peripheral retinal veins in the right eye, and nonperfusion of the peripheral retina but only mild late dye accumulation within the macula.

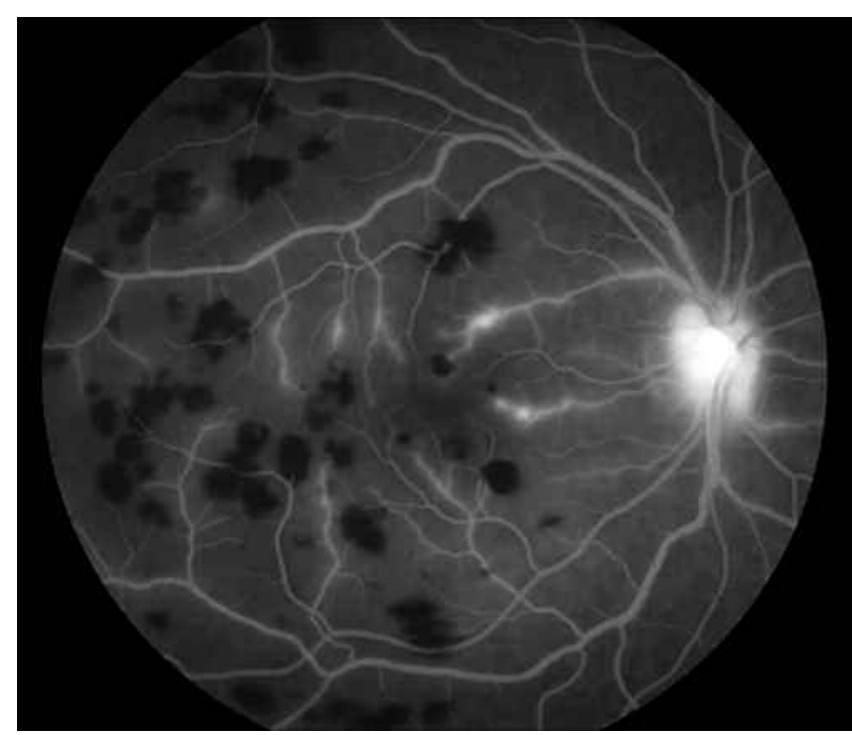

Figure 3. Fluorescein angiogram of the right eye shows significant dye leakage from the optic disc. 


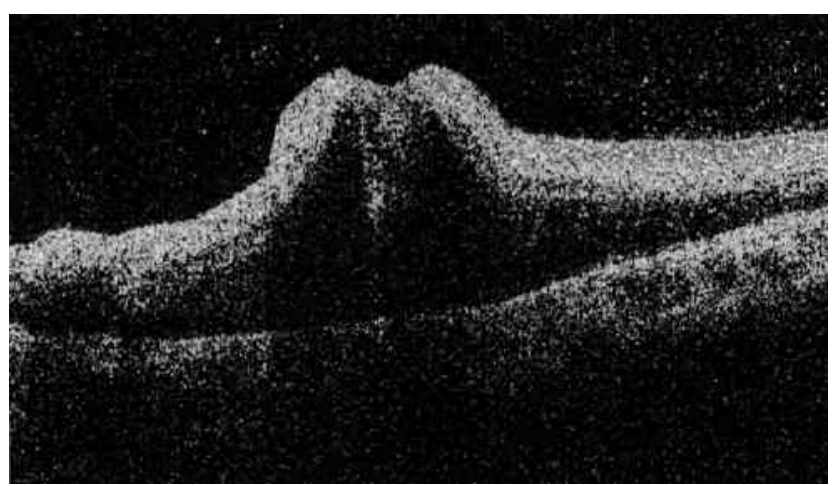

Figure 4. Optical coherence tomography with macular thickness measuring $398 \mu \mathrm{m}$ (normal $<200 \mu \mathrm{m}$ ), consistent with ischemic thickening.

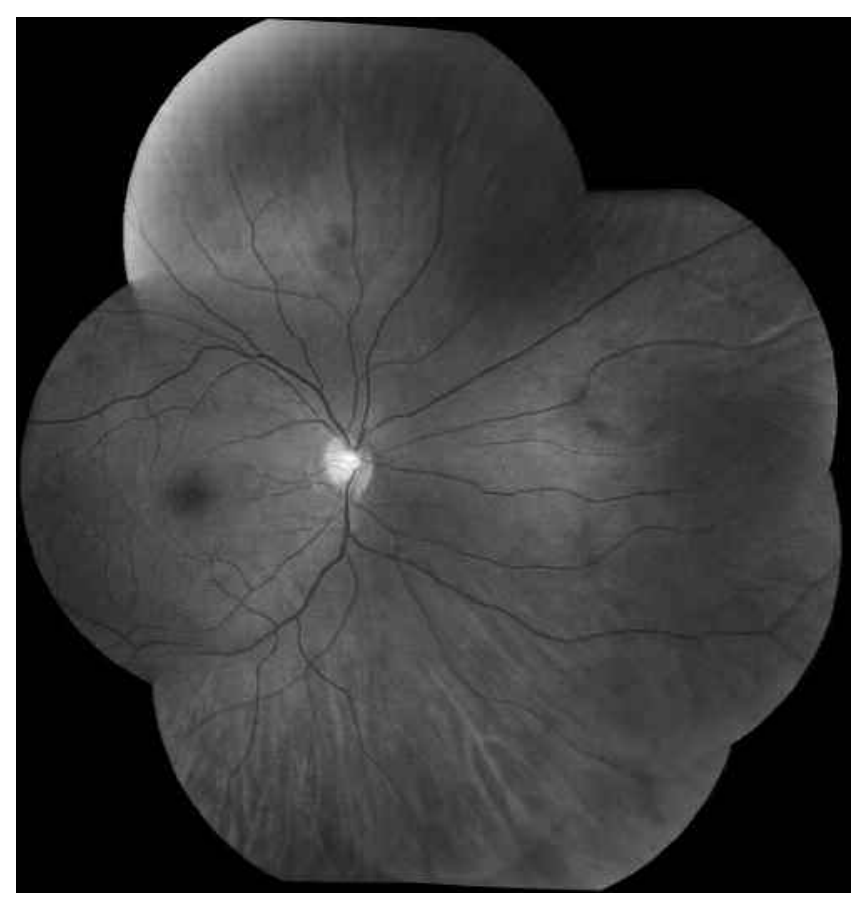

Figure 5. Fundus photography of the right eye shows resolution of all signs of intraocular inflammation. ed 7 monthly infusions of cyclophosphamide. After 2 weeks, visual acuity in the right eye had improved to 20/200 and macular thickening had resolved. Five months later, visual acuity in the right eye measured 20/30, with fundus photography revealing resolution of retinal hemorrhages and intraocular inflammation (Figure 5). Mycophenolate mofetil is currently being used as maintenance therapy.

\section{REFERENCES}

1. Nag TC, Wadhwa S. Vascular changes of the retina and choroid in systemic lupus erythematosus: Pathology and pathogenesis. Curr Neurovasc Res 2006;3:159-68.

2. Paovic J, Paovic P, Vukosavljevic M. Clinical and immunological features of retinal vasculitis in systemic diseases. Vojnosanit Pregl 2009;66:961-5.

3. Neumann R, Foster CS. Corticosteroid-sparing strategies in the treatment of retinal vasculitis in systemic lupus erythematosus. Retina 1995;15:201-12.

4. Hickman RA, Denniston AK, Yee CS, Toescu V, Murray PI, Gordon C. Bilateral retinal vasculitis in a patient with systemic lupus erythematosus and its remission with rituximab therapy. Lupus 2010;19:327-9.

5. Damato E, Chilov M, Lee R, Singh A, Harper S, Dick A. Plasma exchange and rituximab in the management of acute occlusive retinal vasculopathy secondary to systemic lupus erythematosus. Ocul Immunol Inflamm 2011;19:379-81. 